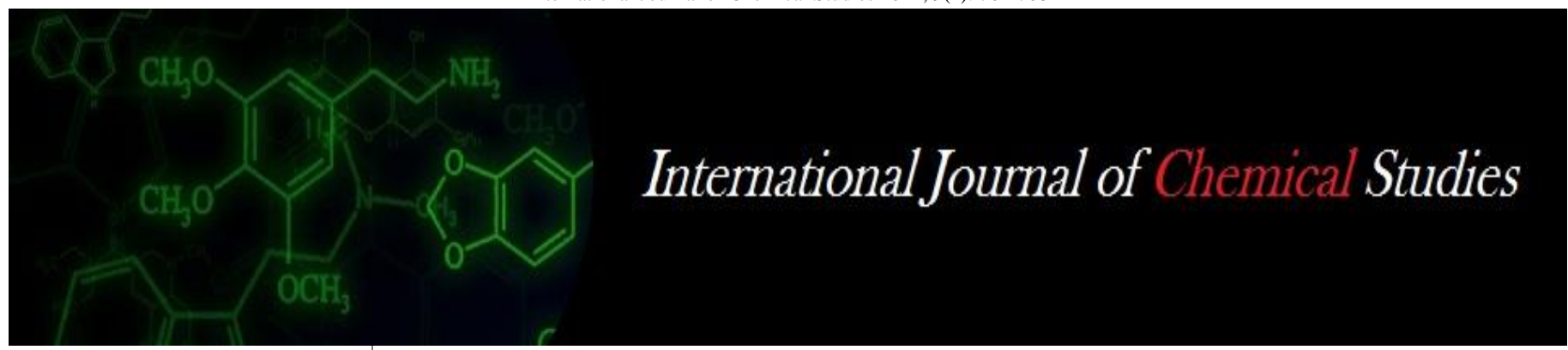

P-ISSN: 2349-8528

E-ISSN: 2321-4902

www.chemijournal.com

IJCS 2021; 9(1): 764-768

(C) 2021 IJCS

Received: 01-10-2020

Accepted: 09-11-2020

\section{RC Meena}

ICAR- All India Coordinated

Research Project on Pearl Millet,

Agriculture University, Jodhpur,

Rajasthan, India

Supriya Ambawat

ICAR-All India Coordinated

Research Project on Pearl Millet,

Agriculture University, Jodhpur,

Rajasthan, India

C Tara Satyavathi

ICAR-All India Coordinated

Research Project on Pearl Millet,

Agriculture University, Jodhpur,

Rajasthan, India

\section{Rajbala Meena}

ICAR- All India Coordinated

Research Project on Pearl Millet,

Agriculture University, Jodhpur,

Rajasthan, India
Corresponding Author: RC Meena

ICAR- All India Coordinated

Research Project on Pearl Millet,

Agriculture University, Jodhpur,

Rajasthan, India

\section{High temperature induced biochemical changes in pearl millet genotypes at seedling stage}

\author{
RC Meena, Supriya Ambawat, C Tara Satyavathi and Rajbala Meena
}

DOI: https://doi.org/10.22271/chemi.2021.v9.i1k.11316

\begin{abstract}
Thirteen genotypes of Pearl millet (Pennisetum glaucum (L.) R. Br.) selected on the basis of heat tolerance were studied to see changes at biochemical and physiological levels. The plants were initially raised under normal condition in small plastic pots and 20 days old seedling were exposed at $\left(40{ }^{\circ} \mathrm{C}\right.$ for 4 hrs, $44{ }^{\circ} \mathrm{C}$ for $4 \mathrm{hrs}$ and $46^{\circ} \mathrm{C}$ for $2 \mathrm{hrs}$ ) in BOD incubator at Mandor to create the heat stress condition. After two days treatment data were recorded for MSI, chlorophyll content, antioxidative enzymes and MDA content. MSI, chlorophyll content and MDA decreased significantly due to heat stress while SOD, and CAT increased significantly under heat stress condition. The genotypic difference was also found significant. In some genotypes R/S increased while in some genotypes R/S ratio decreased under heat stress. The genotypes and PPMI 1053 and PPMI 1087 and HB 17-6 perform better having antioxidative enzymes. The better performance of these genotypes may be due to high RWC, MSI, chlorophyll, SOD, CAT and low MDA content under high temperature stress.
\end{abstract}

Keywords: MSI, MDA, SOD, Pearl millet and Biochemical

\section{Introduction}

Pearl millet [Pennisetum glaucum (L.) R. Br.] is the staple food of majority of the poor and small land holders, as well as feed and fodder for livestock in rainfed regions of the country. In the semiarid tropics, inadequate seedling establishment due to heat stress can reduce productivity and stability of production of pearl millet ${ }^{[1]}$. The temperature is one of the key climatic factors and has profound effect on the growth and development of the pearl millet. The soil temperatures in farmers' field in India and Africa commonly exceed $45^{\circ} \mathrm{C}$ and the temperatures as high as $60^{\circ} \mathrm{C}$ have occasionally been measured. The response of plants to heat stress depends upon the duration and degree of heat stress ${ }^{[2]}$. High temperature exerts negative impact due to inhibition of photosynthesis process ${ }^{[3]}$. One of the major consequences of HT stress is the excess for survival under various environmental stress conditions including HT. Plants continuously struggle plant is able, to some extent, to tolerate heat stress due to physical changes within the plant body and frequently by creative signals for changing metabolism. Plants alter their metabolism in various ways in response to HT, particularly by producing compatible solutes that are able to organize proteins and cellular structures, maintain cell turgor by osmotic adjustment and modify the antioxidant system to re-establish the cellular redox balance and homeostasis. During cruel heat stress, ROS generated as a byproduct of aerobic metabolism negatively affect cellular metabolism, such as peroxidation of lipid membranes and damage to nucleic acids and proteins ${ }^{[4]}$. High temperature stress differentially affects the stability of various membranes, cytoskeleton structures, RNA species and proteins, and alters the effectiveness of enzymatic. Plants turn on enzymatic and non-enzymatic ROS scavenging systems to protect this ROS production. The main ROS scavenging enzymes are superoxide dismutase (SOD), catalase (CAT), peroxidase (POX), ascorbate peroxidase (APX), and glutathione reductase (GR), and the non-enzymatic systems include ascorbic acid (ASC) and glutathione $(\mathrm{GSH})^{[5]}$. High-minded levels of these antioxidants are crucial for imparting thermo tolerance in plants ${ }^{[6]}$. Present investigation was conducted to study High temperature induced biochemical changes in Pearl millet genotypes at seedling stage. 


\section{Materials and Methods}

The experiment was conducted at Mandor, Jodhpur to identify the heat tolerance mechanism in pearl millet at seedling stage. The pearl millet entries HB 17-6, HR 17-6, JMSB20143, JMSB 20101, J-2594, CZI 2010/11, CZI 2007/9, 411B, PPMI 1053, PPMI 1087, PPMI 1213, BIB 240 and BIB 238 used under this study. The plants were initially raised under normal condition in small plastic pots and 20 days old seedling were exposed at $\left(40^{\circ} \mathrm{C}\right.$ for $4 \mathrm{hrs}, 44^{\circ} \mathrm{C}$ for $4 \mathrm{hrs}$ and $46^{\circ} \mathrm{C}$ for $\left.2 \mathrm{hrs}\right)$ in BOD incubator to create the heat stress condition. All the measurements were taken after 2 days of treatment. Second fresh leaves were collected for the analysis.

\section{Chlorophyll extraction ${ }^{[6]}$}

$100 \mathrm{mg}$ of finely cut fresh leaves were taken and grind with $10 \mathrm{ml}$ of $80 \%$ acetone. It was then centrifuged at $5000-10000$ rpm for 5 mins. The supernatant was transferred. The absorbance of the solution was red at $645 \mathrm{~nm}$ and $663 \mathrm{~nm}$.

\section{Estimation of Chlorophyll content}

The concentrations of chlorophyll $\mathrm{a}$, chlorophyll $\mathrm{b}$ and total chlorophyll were calculated using the following equation:

Chlorophyll a: $12.7\left(\mathrm{~A}_{663}\right)-2.69\left(\mathrm{~A}_{645}\right)$

Chlorophyll b: $22.9\left(\mathrm{~A}_{645}\right)-4.68\left(\mathrm{~A}_{663}\right)$

Total Chlorophyll: $20.2\left(\mathrm{~A}_{645}\right)+8.02\left(\mathrm{~A}_{663}\right)$

\section{Membrane stability index}

The procedure described by Premchandra et al. ${ }^{[8]}$ modified and by Sairam ${ }^{[9]}$ was used for calculating membrane stability index. Leaf samples $(0.1 \mathrm{~g})$ were placed in distilled water (10 $\mathrm{ml}$ ). One set was kept at $40^{\circ} \mathrm{C}$ for 30 minutes and its conductivity of electrolytic leakage (C1) was recorded using conductivity meter. The second set was kept in boiling water bath $\left(100{ }^{\circ} \mathrm{C}\right)$ for 10 minutes and its conductivity (C2) was recorded after cooling at room temperature.

The MSI was calculated according to the formulae:

$$
\mathrm{MSI} \%=(1-\mathrm{C} 1 / \mathrm{C} 2) \times 100
$$

\section{Determination of Malondialdehyde}

Determination of Malondialdehyde (MDA) concentration was determined by the method described by Heath and Packer ${ }^{[10]}$. Two hundred $\mathrm{mg}$ fresh leaf samples were extracted in $5.0 \mathrm{ml}$ of $6 \%$ trichloroacetic acid (TCA) solution, centrifuged at $8000 \mathrm{rpm}$ for 10 minute. Two $\mathrm{ml}$ of Thio-Barbituric Acid (TBA) reagent was added in $1 \mathrm{ml}$ of supernatant, mixed well and incubated for half an hour in a boiling water bath. Later the tubes were cooled to room temperature. The assay mixture was then centrifuged at $5000 \mathrm{rpm}$ for 10 minutes. Supernatant bearing yellow to light orange colour was read on spectrophotometer at two wavelengths viz. $532 \mathrm{~nm}$ (major for MDA) and 600 (minor for interfering substance) millimolar concentration of MDA was calculated as follows: MDA (mM) $=($ O.D.532-O.D. 600) x 155 (extinction coefficient).

\section{Antioxidant enzyme essays}

Superoxide dismutase (SOD) assay was performed as per protocol of Dhindhsa et al. ${ }^{[11]}$. Leaf sample $(0.5 \mathrm{~g})$ was homogenised in $10 \mathrm{~cm}^{3}$ chilled $0.1 \mathrm{M}$ potassium phosphate buffer ( $\mathrm{pH} 7.5$ ) containing $0.5 \mathrm{mM}$ EDTA. The buffer was filtered through cheesecloth, and after centrifugation at $20,000 \mathrm{X} \mathrm{g}$ for $20 \mathrm{~min}$, aliquots of the supernatant were used for enzymatic quantify. The $3.0 \mathrm{~cm} 3$ reaction mixture contained $13 \mathrm{mM}$ methionine, $25 \mathrm{mM}$ nitroblue tetrazolium chloride (NBT), $0.1 \mathrm{mM}$ EDTA, $50 \mathrm{mM}$ phosphate buffer $\mathrm{pH}$ (7.8), $50 \mathrm{mM}$ sodium bicarbonate and $0.1 \mathrm{~cm} 3$ enzyme extract. The reaction was started by adding $2 \mathrm{~lm}$ riboflavin and placing the tubes below $2 \mathrm{X} 15.00 \mathrm{~W}$ fluorescent lamp for $15 \mathrm{~min}$. It was stopped by switching off the light and covering the tubes with black cloth. Tubes without enzyme develops maximum colour. A non-irradiated complete reaction mixture did not develop colour and served as blank. Absorbance was recorded at $560 \mathrm{~nm}$, and one unit of enzyme activity was taken as that quantity of enzyme, which reduced the absorbance reading to $50 \%$ in comparison with the tubes lacking enzymes.

The catalase (CAT) activities were assayed as per the protocol of Chance and Maehly ${ }^{[12]}$. Samples were prepared by grinding $0.5 \mathrm{~g}$ fresh leaves in ice-cold $50 \mathrm{mM}$ potassium phosphate buffer ( $\mathrm{pH}$ 7.0) containing $0.1 \mathrm{mM}$ ethylene diamine tetra acetic acid (EDTA) and $1 \%$ polyvinyl polypyrrolidone (PVP). The homogenate was filtered through four layers of cheese cloth and then centrifuged at $4 \mathrm{C}$ for 20 min at $15,000 \mathrm{X}$ g. The supernatant was collected and an appropriate aliquot dilution of the crude extract was used for enzyme assays. CAT activity was measured by following the decomposition of $\mathrm{H}_{2} \mathrm{O}_{2}$ at $240 \mathrm{~nm}(\mathrm{e}=39.4 \mathrm{mM}-1 \mathrm{~cm}-1)$ in a reaction mixture containing $50 \mathrm{mM}$ phosphate buffer ( $\mathrm{pH} 7.0$ ) and $15 \mathrm{mM} \mathrm{H}_{2} \mathrm{O}_{2}$. Enzyme activity was expressed as lmol of $\mathrm{H}_{2} \mathrm{O}_{2}$ decomposed mg-1 (protein) min-1.

\section{Results and Discussion}

Pearl millet crop responds to high temperature stress in the form of changes in various physiological, biochemical processes. In the present study, with thirteen genotypes alter in small plastic pots to high temperature stress, physiological index (membrane stability index) have been observe when crop in the heat stress. Besides, key biochemical parameters were also measured (viz., MDA; superoxide dismutase (SOD), catalase (CAT), and chlorophyll. All these parameters helped in assessing tolerant versus susceptible genotypes at biochemical levels to heat stress. The values for stability of cellular membrane in the pearl millet genotypes revealed that there was decline in MSI percent of stressed plant in all genotypes. The MSI values varied from 77.40 to 87.99 percent on fresh weight basis at control $40{ }^{\circ} \mathrm{C}$ while under stress varied from 67.17 to 76.47 percent. MSI was high JMSB 20143 followed by J 2594, CZI 2010/11 and BIB 238 at control $40^{\circ} \mathrm{C}$, whereas, HB 17-6,HR 17-6 followed by JMSB 20143 and PPMI 1213 high MSI was recorded at $46{ }^{\circ} \mathrm{C}$ (Figure-1). The difference in degree of lowering of MSI values was found significant when treatments were compared. Stress induced membrane damage has been biochemically marked by the presence of MDA as one of the thiobarbituric acid reducing substances (TBARS) that accumulats as a consequence of membrane lipid peroxidation. The MDA values in stressed plants were found higher over respective controls in all the genotypes. MDA content varied from 222 to 486 content $\mu \mathrm{mol}$ g- 1 f.wt under control, while under stress it varied from 308 to $570 \mu \mathrm{mol}$ g- 1 f.wt. The MDA content was minimum increase in genotype BIB 238 with at par BIB 240 and PP1213 at $46^{\circ} \mathrm{C}$ (Figure-2). Reactive oxygen species are known to damage cellular membranes by inducing lipid peroxidation ${ }^{[13]}$. Membrane stability index may be used as parameter to estimate the cellular injury caused to membrane due to peroxidation of fatty acids of the membrane. In present study, the increased levels of MDA in stress condition indicated the membrane sensitivity/membrane damage due to heat stress. Lower rate of increase of MDA in genotypes 
indicated better membrane strength. In the present study, the MSI reductions were found lowest in genotypes BIB 240 and PPMI 1053 indicating that they are putatively tolerant at 46 ${ }^{\circ} \mathrm{C}$. Similar result were observed by other researchers ${ }^{[14-18]}$. Amon many quaternary ammonium compounds is synthesized or found abundant mainly in chloroplast where it plays a vital role in adjustment and protection of thylakoid membrane thereby maintaining photosynthetic efficiency. The content of total chlorophyll varied from 0.71 to $1.63 \mathrm{mg}$ g- 1 fresh weight under control $40{ }^{\circ} \mathrm{C}$ while under $46{ }^{\circ} \mathrm{C}$ stress it varied from 0.47 to $1.09 \mathrm{mg}$ g- 1 at $46{ }^{\circ} \mathrm{C}$ (Figure-3). Plants must be protected from heat-induced oxidative stress so that they can survive under HT. Tolerance to HT stress in crop plants has been associated with an increase in antioxidative capacity ${ }^{[19-}$ 20]. Tolerant plants entail a tendency of protection against the damaging effects of ROS with the synthesis of various enzymatic and nonenzymatic ROS scavenging and detoxification systems ${ }^{[21]}$. Activities of different antioxidant enzymes are temperature sensitive and activation occurs at different temperature ranges but the activities of these enzymes increase with increasing temperature. Catalase and Superoxide dismutase are the most important enzymes involved in regulation of intracellular level of $\mathrm{H}_{2} \mathrm{O}_{2}$. Variability in increasing the activities of these antioxidants across wheat genotypes indicates their differential ability to acquire thermo-tolerance. Catalase activity was maximum in PPMI 1053, PPMI 1213 and HB 17-6 at $46{ }^{\circ} \mathrm{C}$ (Figure-4). SOD is usually considered as the first line of defence against oxidative stress. In present study, the activities of catalase and superoxide dismutase enhanced with variable magnitude under heat stress conditions. Among genotypes, maximum percent increase in catalase and superoxide dismutase were recorded in PPMI 1053, PPMI 1087 and HB 17-6 (Figure-5) under high temperature stress conditions. The temperature until which increased activities are maintained varies in the tolerant and susceptible varieties. In the tolerant varieties, they could maintain increased activities at HT in comparison to the susceptible ones ${ }^{[22]}$

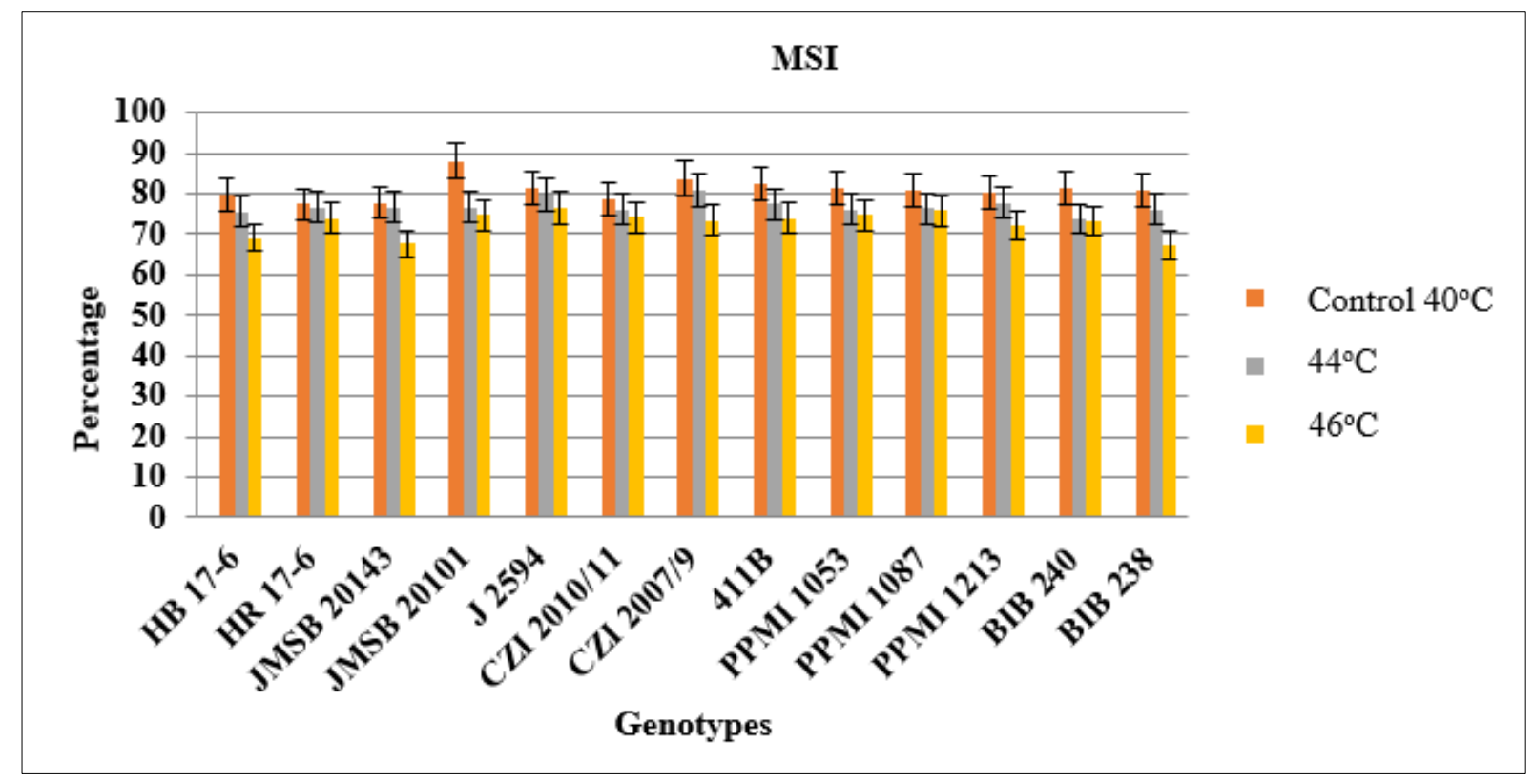

Fig 1: Effect of high temperature stress on membrane stability index in pearl millet genotypes. Values of \pm SE

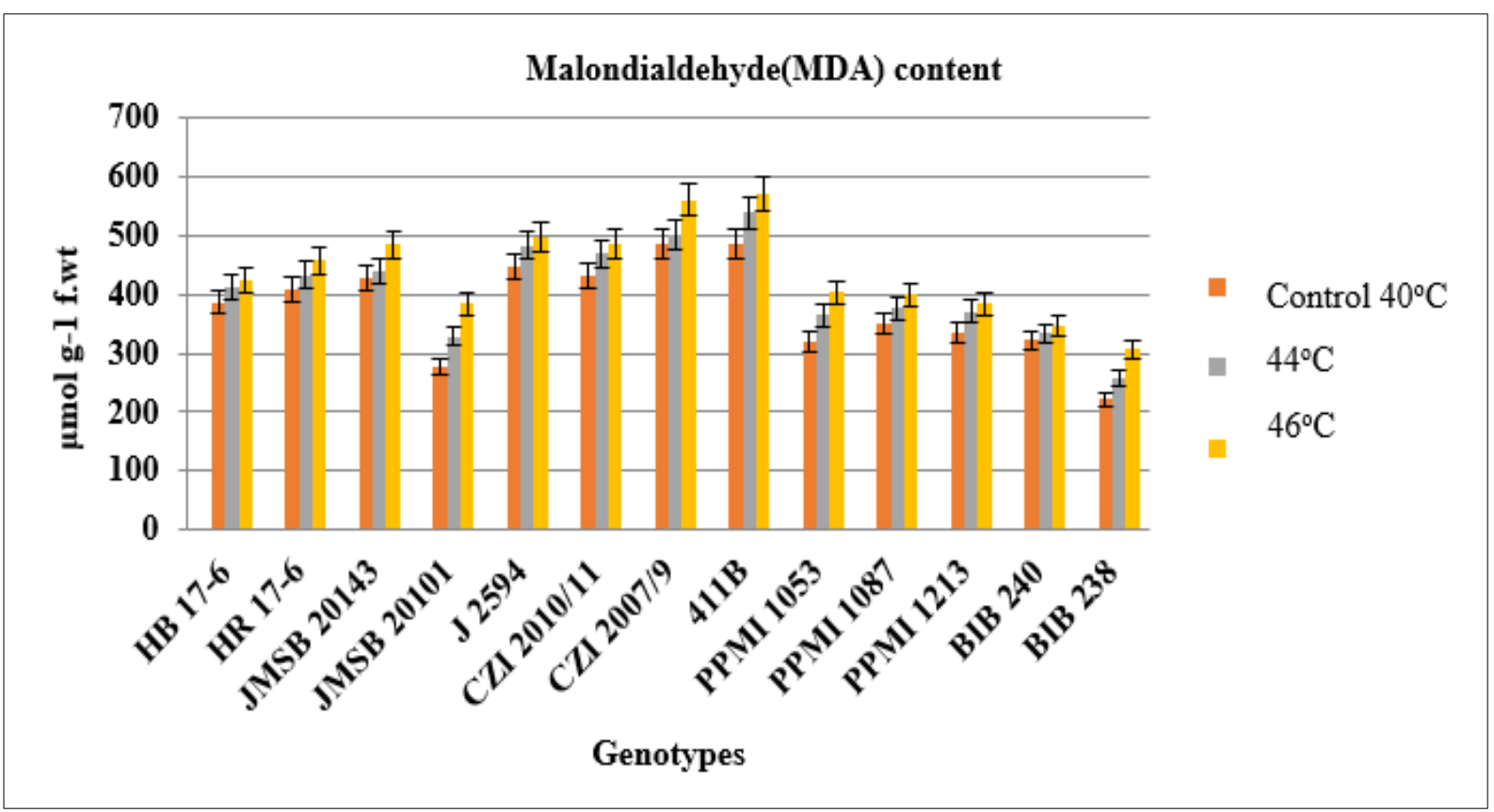

Fig 2: Effect of high temperature stress on Malondialdehyde (MDA) content in pearl millet genotypes. Values of $\pm \mathrm{SE}$ 


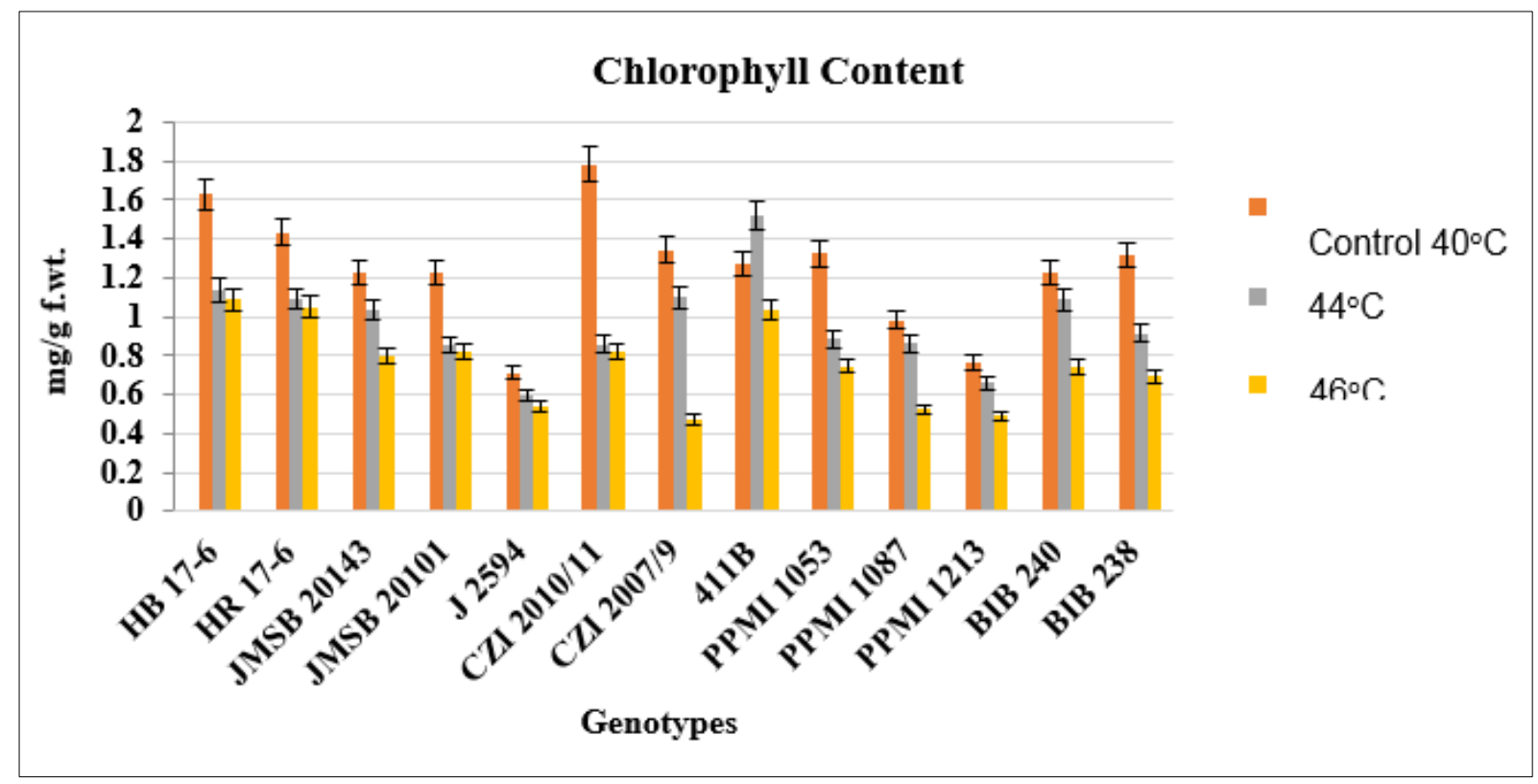

Fig 3: Effect of high temperature stress on Chlorophyll content in pearl millet genotypes. Values of \pm SE

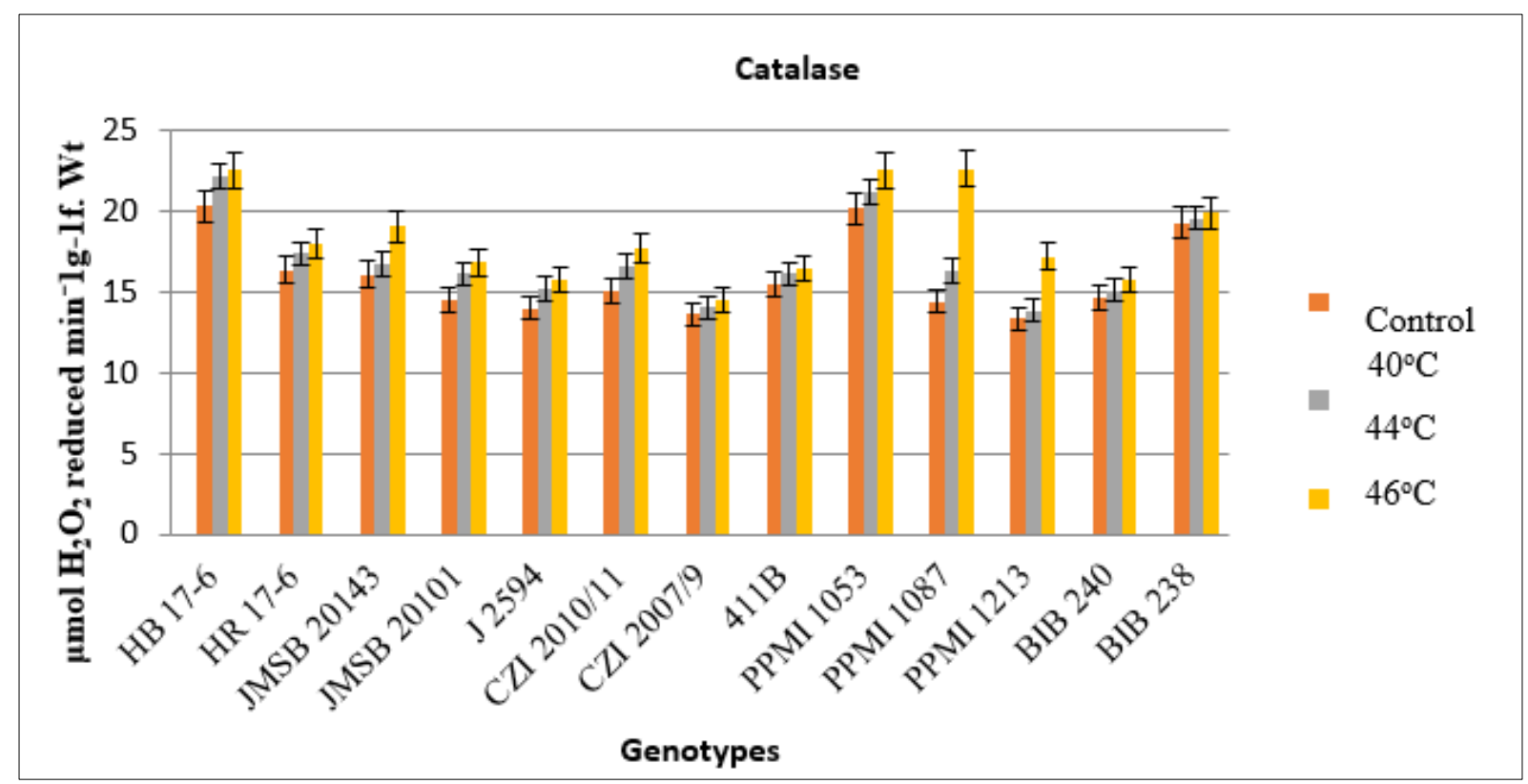

Fig 4: Effect of high temperature stress on antioxidant enzyme catalase in pearl millet genotypes. Values of $\pm \mathrm{SE}$

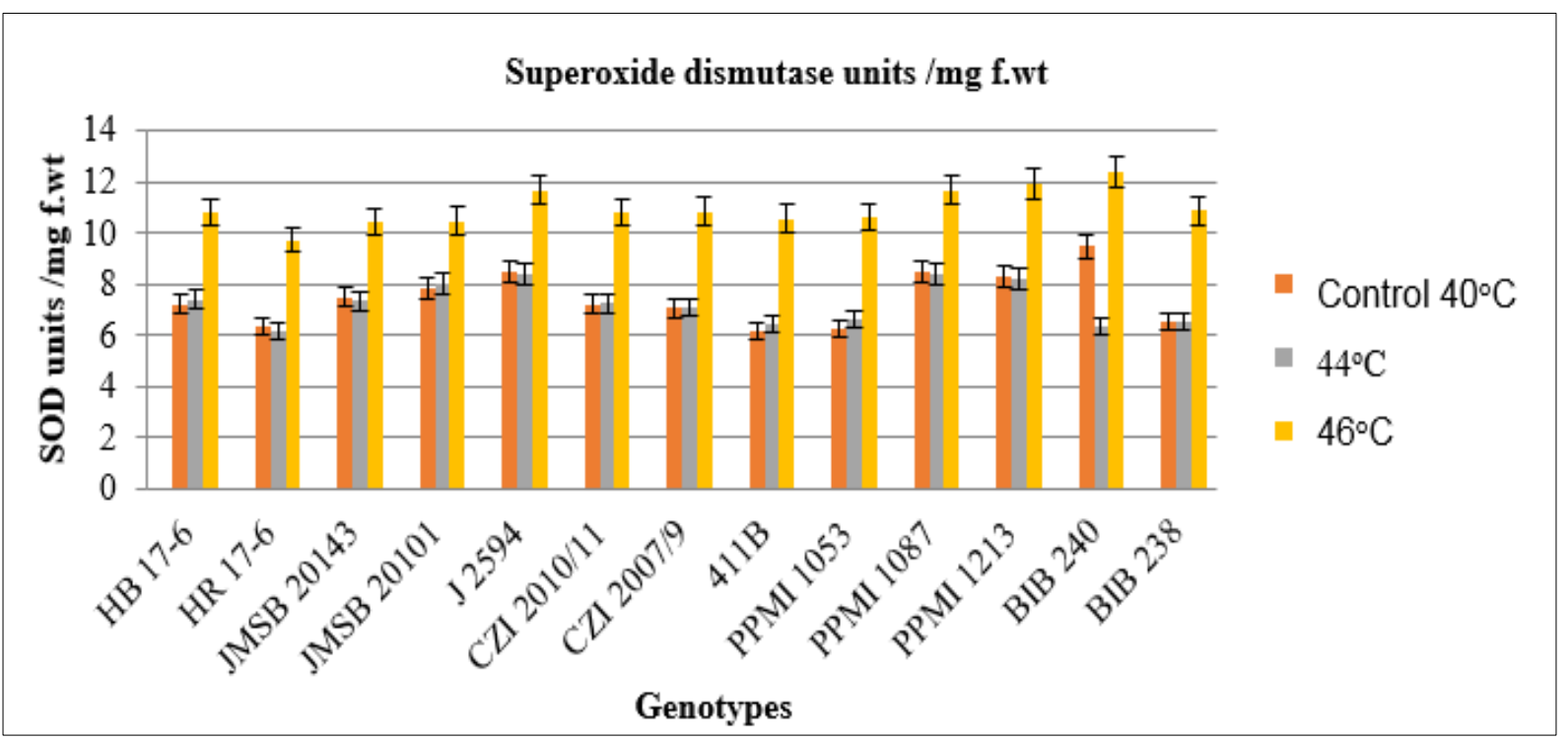

Fig 5: Effect of high temperature stress on activity of antioxidant enzyme Superoxide dismutase in pearl millet genotypes. Values of \pm SE 


\section{Conclusion}

High temperature stress is one of the most prevalent types of abiotic stress which directly induces plant desiccation. The plants occurrence strict osmotic stress and production of ROS, which damages the nucleic acid and protein structures. The results of present study reveald that tolerance mechanism for heat stress exists in pearl millet genotypes for a variable extent. On the basis of various parameters analyzed in this study, PPMI 1053, PPMI 1087 and HB 17-6 have been identified as heat tolerant and BIB 238 and BIB 240 as heat susceptible. It is suggested that these heat tolerant genotypes can be used in future breeding programme and information can be used for molecular analysis for study towards the development of a heat tolerant pearl millet hybrids.

\section{Acknowledgement}

We are thankful to ICAR, New Delhi for providing financial assistance to ICAR- All India Coordinated Research Project on Pearl Millet, Jodhpur.

\section{References}

1. Peacock JM, Soman P, Jayachandran R, Rani AU, Howarth CJ, Thomas A. Effects of high soil surface temperature on seedling survival in pearl millet. Exp Agric 1993;29:215-225.

2. Hasanuzzaman M, Nahar K, Alam MM et al. Physiological, biochemical, and molecular mechanisms of heat stress tolerance in plants. International Journal of Molecular Sciences 2013;14:9643-9684.

3. DeRidder BP, Salvucci ME. Modulation of Rubisco activase gene expression during heat stress in cotton (Gossypium hirsutum L.) involves post-transcriptional mechanisms. Plant Science 2007;172:246-254.

4. Bita CE, Gerats T. Plant tolerance to high temperature in a changing environment: scientific fundamentals and production of heat stress-tolerant crops. Frontiers in Plant Science 2013;4:273.

5. Suzuki N, Koussevitzky S, Mittler R, Miller G. ROS and redox signalling in the response of plants to abiotic stress. Plant Cell Environ 2012;35:259-270. doi: 10.1111/j.1365-3040.2011.02336.x

6. Awasthi R, Bhandari K, Nayyar H. Temperature stress and redox homeostasis in agricultural crops. Front. Environ. Sci 2015;3:11. doi: 10.3389/fenvs. 2015.00011

7. Arnon DI. Copper enzymes in isolated chloroplast, polyphenol oxidase in Beta vulgaris. L. Plant physiology 1949;24:1-15.

8. Premchandra GS, Saneoka H, Ogata S. Cell membrane stability, an indicator of drought tolerance as affected by applied nitrogen in soybean. Journal Agric. Sci. Camb 1990;115:63-66.

9. Sairam RK. Effect of moisture-stress on physiological activities of two contrasting wheat genotypes. Indian J Experimental Biology 1994;32:594-597.

10. Heath RI, Packer L. Photoperoxidation in isolated chloroplast. Kinetics and stoichiometry of fatty acid peroxidation. Archive Biochemistry Biophysics 1968;125:189-198.

11. Dhindhsa RS, Plumb-Dhidsa P, Thorne TA. Leaf senescence: correlated with increased levels of membrane permeability and lipid per oxidation, and decreased levels of superoxide dismutase and catalase. J Expt Bot 1981;32:93-101.

12. Chance B, Maehly AC. Assay of catalase and peroxidises. Methods Enzymol 1955;2:764-775.
13. Devi RS, Prasad MNV. Copper toxicity in Ceratophyllum demeresum L. (Coontail), a free floating macrophyte: Response of antioxidant enzymes and antioxidants, Plant Sciences 1998;138:157.

14. Maavimani M, Jebaraj S, Raveendran M et al. Cellular membrane thermostability is related to rice (Oryza sativa L.) yield under heat stress. International Journal of Tropical Agriculture 2014;32:201-208.

15. Golam F, Prodhan ZH, Nezhadahmadi A, Rahman M. Heat tolerance in tomato. Life Science Journal 2012;9:1936-1950.

16. Blum A, Klueva N, Nguyen HT. Wheat cellular thermotolerance is related to yield under heat stress. Euphytica 2001;117:117-123.

17. Wahid A, Shabbir A. Induction of heat stress tolerance in barley seedlings by pre-sowing seed treatment with glycinebetaine. Plant Growth Regulation 2005;46:133141.

18. Gupta NK, Agrawal Shurbi Agrawal VP, Gupta S, Singh G. Effect of short-term heat stress on growth, physyiology and antiozxidative defence system in wheat seedling. Acta Physiol Plant 2013, DOI10.1007/s11738013-1122-1.

19. Almeselmani M, Deshmukh PS, Sairam RK, Kushwaha SR, Singh TP. Protective role of antioxidant enzymes under high temperature stress. Plant Sci 2006;171:382388, 117.

20. Devraj VR. High temperature and salt stress response in French bean (Phaseolus vulgaris). Aust. J Crop Sci 2008;2:40-48.

21. Apel K, Hirt H. Reactive oxygen species: metabolism, oxidative stress and signal transduction. Ann. Rev. Plant Biol 2004;55:373-399.

22. Chakraborty U, Pradhan D. High temperature-induced oxidative stress in Lens culinaris, role of antioxidants and amelioration ofstress by chemical pre-treatments. J Plant Interact 2011;6:43-52. 